\title{
How Does Language Influence Performance, Fear and Attitudes towards Mathematics at Primary School Level in Zimbabwe?
}

\author{
Silvanos Chirume: Senior Lecturer, Department of Mathematics and Statistics, Zimbabwe Open University, \\ Midlands Regional Campus, Zimbabwe
}

\begin{abstract}
This mixed-methods (QUANT-qual) study compares test performances of two classes of 52 (26 in each class) Grade 5 learners in a multiple choice Maths test written in English language (Group A) and the same test but with questions written in Shona language (Group B), respectively. The paper also examines the role of language in the development of attitudes and fear of mathematics by learners at the same primary school in Gokwe district, Zimbabwe. Results showed that there were significant differences (in favour of the English language) between Group A's performance and Group B's performance. Other findings were that teachers had mixed feelings towards the use of mother tongue in teaching and learning primary school mathematics, but generally agreed that the language of instruction and/or learning affect performance in mathematics, attitudes towards mathematics and fear of mathematics. The paper concludes that using mother tongue as a medium of instruction in the teaching of mathematics in the Zimbabwean junior primary schools is desirable but the feasibility could not be established. It is recommended, among other things, that there is need for further research and policy formulation on the language of learning/instruction at various school levels in Zimbabwe.
\end{abstract}

Key words: Mother tongue, Role of language, Shona, Mathematics performance, Fear of mathematics, Negative attitude to mathematics.

\section{Introduction}

In line with the Niziramasanga Commission's (1999) recommendations and the need to regain its status as the breadbasket of Southern Africa and also to compete with other countries on the economic, technological and educational fronts, Zimbabwe has recently introduced a new curriculum framework for primary and secondary education for the years 2015-2022. According to this new curriculum framework, the new junior Maths curricula for Grades 3 to 7 (Curriculum Development and Technical Services, 2015, p. 2) seems to be silent on whether teachers or learners can use the learners' first language (or mother tongue) as the language of learning and/or instruction but outlines one of its syllabus aims as, “... to help leaners to think and express themselves clearly and logically." English being a 'foreign' and second language to most learners, and also according to the old curriculum, English being the language of instruction and learning, one would wonder how the learners are supposed to 'think and express themselves clearly and logically.'

In their case studies Buhmann and Trudell (Unesco, 2008, p. 5) point out that, "The research evidence today clearly shows that using the learners' mother tongue is crucial to effective learning." Another study by Mufanechiya and Mufanechiya (2011) which employed the descriptive survey method investigated whether the use of mother tongue as a medium of instruction in the teaching of mathematics in the Zimbabwean junior primary schools was desirable or feasible. These two and other studies prompted the researcher to carry out a mini- experimental study to find out whether (a) it would be feasible or practical for learners to write a math test in Shona, (b) learners would perform better in the Math test whose questions were written in Shona than

Vol. 2, No. 2 pp. 36-43

2019

DOI: $10.53935 / 2641-533 x . v 2 i 2$

Funding: This study received no specific

financial support.

Article History:

Received: 14 January 2019

Revised: 8 February 2019

Published: 20 March 2019

(0) 2019 by the authors; licensee Academic Publishing Group

36 
in the Maths test whose questions were written in English, and (c) teachers would prefer to use English, or Shona or both as languages of instruction.

\subsection{Hypotheses}

The research (null) hypotheses were:

$1 \mathrm{H}_{0}$ : There is no significant difference between Grade 5 learners' performance in a Maths multiple choice test presented in English and Grade 5 leaners' performance in the same test but presented in the Shona language (to be rejected).

$2 \mathrm{H}_{0}$ : Performance in mathematics does not depend on the language of learning (to be rejected).

$3 \mathrm{H}_{0}$ : Performance in mathematics does not depend on the language of instruction (to be rejected).

$4 \mathrm{H}_{0}$ : Continued difficulty of mathematical understanding due to language does not develop negative attitudes towards mathematics (to be rejected).

$5 \mathrm{H}_{0}$ : Lack of understanding of mathematics due to language does not generate fear of mathematics (to be rejected).

\subsection{Research Questions}

The research questions for this study were:

1. What is the role of the language of instruction towards the development of primary school learners' attitudes towards mathematics?

2. To what extent does the language of learning contribute to learners' fear of mathematics at primary school level?

3. How does the use of mother tongue influence primary school learners' performance in a mathematics test?

\section{Review of Related Literature}

The problem of learners failing in the proper verbal and written communication and comprehension in the classroom has been with teachers since schooling began and is not the problem of language teachers alone. In mathematics, a lot of research on the effect of language on performance has been carried out (Abubakar, Umar, and Musawa, 2015; Awan, Azher, Anwar, and Naz, 2010; Buhmann, and Trudell, 2008).

Abubakar, Umar, and Musawa (2015) report that junior secondary school students in Katsina State of Nigeria who were taught using their mother tongue (Hausa language) performed better in a mathematics achievement test than those who were taught using English. However, mathematics has specialised symbols and terminology and therefore there is a difference between general English language and mathematical language even if it is expressed in English. In support of this view, Awan, Azher, Anwar, and Naz (2010) strongly believe that mathematics is related to language. The authors further say if students find mathematics to be difficult and cannot solve problems due to lack of understanding (as a result of language), they will end up disliking and fearing the subject of mathematics (Awan, Azher, Anwar, and Naz, 2010).

In 1987 a programme called 'Pédagogie Convergente' (or Convergent Pedagogy) was introduced in Mali (Buhmann and Trudell, 2008). According to Buhmann and Trudell (2008, p. 9):

The term convergence describes a pedagogy that emphasizes interactive learning and links teaching methods of the first and second languages. The child's mother tongue is used as the language of instruction throughout primary school and the second language is taught in such a way that the learners become functionally bilingual. The goals of this model are to improve school access and learning outcomes for students, to integrate the school into the social and cultural environment of the students, and to produce functionally bilingual learners.

International Journal
Vol. 2, No. 2 pp. $36-43$ 2019

DOI: $10.53935 / 2641-533 x . v 2 i 2.23$

Email:skchirume@gmail.com

Funding: This study received no specific

financial support.

Article History:

Received: 14 January 2019

Revised: 8 February 201

Accepted: 1 March 2019

Published: 20 March 2019

(C) 2019 by the authors; licensee Academic

Publishing Group

| 37
Buhmann and Trudell (2008) further report that students enrolled in the Convergent Pedagogy Programme had higher mathematics achievement scores than their counterparts in the French only schools; French being the second language and also the language of instruction.

Studies of correlations between mathematics achievement and language achievement have been undertaken. For example, Flouris, Calogiannakis-Hourdakis, Spiridakis, and Campbell (1994) tested 7595 th 
and 6th grade students from various schools in Greece in language and mathematics using the Greek curriculum. They found that the coefficient of correlation between mathematics achievement and language achievement for boys was $r=0.25$ while that for girls was $r=0.28$. These figures, though positive, are quite small probably suggesting that the relationship between language and mathematics achievement might be significant but not very strong.

Some findings pertaining to the role of foreign language on learning in general have been documented. For example, Horwitz (2001) has reviewed several studies where foreign language anxiety was found to correlate negatively with language achievement, and with achievement in other areas. Thus the use of foreign language or second language in schools has been viewed with mixed feelings. Kaphesi (2002) and Mufanechiya and Mufanechiya (2011) support this by citing examples of teachers who had negative attitude towards use of Chichewa in mathematics and some towards English (in Malawi) and pupils and teachers who had negative attitude towards the use of mother tongue (Shona and Isindebele) in Zimbabwe, respectively. This is to be expected because the mathematics leaner often has a 'double jeopardy' of trying to understand the mathematics and at the same time trying to understand the language through which the mathematics is conveyed.

Now in the absence of sufficient and relevant published research data on the role of language, the use of mother tongue and mathematics achievement in Zimbabwean schools, it is most probable that the degree and intensity of negative attitudes and anxiety (mathephobia) and their consequences are overlooked and underreported. Thus this study undertakes to investigate the influence of language on leaners' performance and its role towards development of attitudes and fear of mathematics at primary school level in Zimbabwe.

\section{Theoretical Framework}

This study is based on Cummins' (1981) theory on bilingual students' learning and Sfard's (2008) 'commognition' theory. According to Cummins (1981), a student's language competence is an important factor on that student's mathematics learning. Cummins (1981) further says that it is important for bilingual students to be competent in their first language as well as in their second language in order to learn mathematics better and called this 'balanced bilingualism'. Thus language proficiency is considered to contribute positively to mathematics achievement. Sfard (2008) views thinking (cognition) as a form of communication; this communication being interpersonal. She also says that mathematical learning involves extending one's discourse; discourse being the use of language, symbolic expressions, kinds of thinking, feeling, believing, valuing and acting that can be used to identify oneself as a member of a social group or community. 'Commognition' is therefore a blend of various types of communication and types of cognition (or thinking). In Zimbabwe, English is the language of learning and also the language of teaching from junior primary school upwards (except when the indigenous languages themselves are the learning areas or subjects of study). Thus the above theories imply that in the Zimbabwean context most school leaners' thinking, communication and achievement are affected by the fact of being bilingual or even multilingual since some learners speak more than three languages but with varying degrees of proficiency. This study is therefore contextualised by borrowing ideas from the theories of 'commognition' and bilingualism with the hope of contributing to the debate of 'the use of mother tongue policy.'

\section{Materials and Methods}

This study employed a mixed-methods (QUANT-qual) approach to compare test performances of two similar classes of 52 (26 in each class) Grade 5 learners in a Maths test written in English language (Group A) and the same test but with questions written in Shona language (Group B), respectively. The learners were firstly combined, told of the task at hand and then randomly assigned to the two groups A and $\mathrm{B}$. The learners then wrote the two tests at the same time in one large room under the supervision of the researcher and one of the teachers. The test had ten multiple choice items which covered some aspects of the syllabus (area of rectangles, abacus, fractions, speed, time and distance, compass directions, addition and subtraction of money, rounding off decimals). The test items (in English) were taken from a previous Grade 5 paper which had been checked for validity and reliability. After translating the items into Shona language, the researcher discussed them with colleagues and also sought advice from teachers in the target population after which it was agreed that the test items could measure what they were supposed to measure. The duration of each test was 20

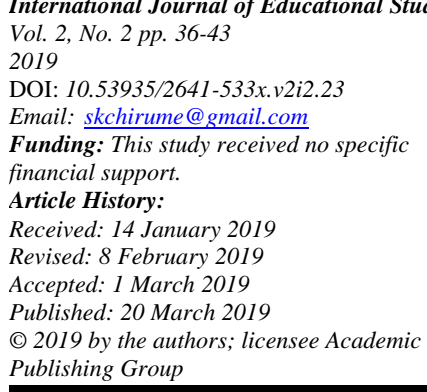

minutes. The study also examined the role of language in the development of attitudes and fear of 
mathematics by learners by way of a teachers' questionnaire with both closed and open ended questions given to six teachers at the same primary school in Gokwe district, Zimbabwe. The same teachers' questionnaire was also administered to ten purposively selected teachers in five randomly selected schools in the same cluster. Thus a total of 16 teachers completed the questionnaire.

\section{Results and Discussion}

\subsection{Grade 5 Leaners' Test Results}

The statistical package SPSS 21 was used to compute summary statistics and to analyse the data. A comparative analysis of the Grade 5 Group A and Group B leaners' test results is presented in Table 1 below.

Table-1. Showing summary statistics for Group A and Group B leaners ( $\mathrm{n}=52)$

\begin{tabular}{lll}
\hline & Maths Test in English (Group A) & Maths Test in Shona (Group B) \\
\hline Mean & 3.2692 & 2.2308 \\
Standard deviation & 1.15092 & 1.03180 \\
Mode & 3 & 3 \\
Median & 3.3525 & 2.2941 \\
Minimum mark & 1 & 0 \\
Maximum mark & 5 & 4 \\
\hline
\end{tabular}

By studying the figures in Table 1, it would appear that the leaners who wrote the Maths test which was presented in English language (Group A) performed better that their counterparts who wrote the Maths test which was presented in the Shona language (Group B). This seems to contradict the confirmed hypothesis that primary school students learn mathematical concepts well using their home language (Hafiz and Farik, 2016).

The leaners' marks were converted to percentages. The researcher then used $30 \%, 40 \%$ and $50 \%$ cut-off rules to determine the percentage of learners who had scored above these 'cut-offs.' It was found that $77.7 \%$ of Group A leaners scored above $30 \%$ compared to $46.2 \%$ of Group B learners who scored above $30 \%$. It was also found that $44.4 \%$ of Group A learners scored above $40 \%$ as compared to $7.7 \%$ of Group B learners who scored above $40 \%$, and again $14.8 \%$ of Group A learners scored above $50 \%$ as compared to $0 \%$ of their Group B counterparts who scored above $50 \%$.

Spearman's correlation between Group A and Group B scores was computed. The results showed that there was a positive but small and non-significant correlation between Group A and Group B marks ( $\mathrm{r}=0.181$, $\mathrm{p}=0.375$ ).

An independent samples t-test was also run to determine if the means in Table 1 were significantly different (at $\alpha=5 \%$ ). Results showed that Group A performed better than Group B, so there was a significant difference between Group A and Group B marks ( $\mathrm{t}=3.187, \mathrm{p}=0.00247$, two tailed). Thus the first null hypothesis, $1 \mathrm{H}_{0}$ (There is no significant difference between Grade 5 learners' performance in a Maths multiple choice test presented in English and Grade 5 leaners' performance in the same test but presented in the Shona language) was rejected.

Several reasons could be attributed to these disparities in learners' performances; one of them being that perhaps the learners had been used to mathematics tests written in English and that perhaps most Group B learners found the mathematics test written in Shona difficult to comprehend as the researcher had translated it using standard Shona which could be slightly different from the leaners' local Shona dialect. These observations corroborate Kazima (2008) who pointed out the difficulties associated with translating maths vocabulary (which is in English) into mother tongue, and also Mufanechiya and Mufanechiya (2011, p. 194) who found out that there were challenges faced by teachers and learners in the classrooms in their attempt to use mother tongue in the teaching and learning of mathematics at junior primary level. However, it would be worthwhile to carry out further research since in another study, Abubakar, Umar and Musawa (2015) found out that junior secondary school students who were taught mathematics in Hausa language performed better than their counterparts who were taught mathematics in English.

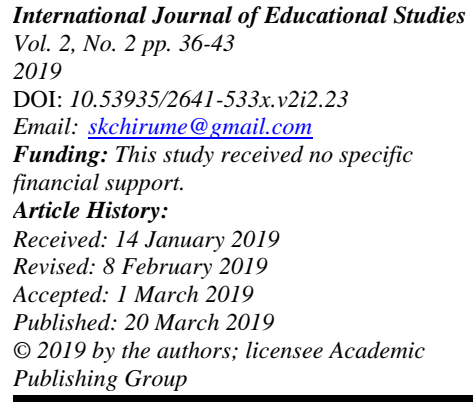

\subsection{Teachers' Questionnaire (Quantitative) Data}

Section A: Biographical Data of the Teachers, $n=16$

Ten $(62.5 \%)$ male and six $(37.5 \%)$ female primary school teachers responded to the questionnaire. This information supports the researcher's observation that most senior primary school classrooms (Grade 4 and 
above) are manned by male teachers while most female teachers teach the junior classes. However, female teachers constitute the majority in most primary schools in Zimbabwe and most male teachers constitute the majority in the secondary schools. The respondents were of the age ranges 31-40 years (31.3\%) and 41-50 years $(68.7 \%)$, with the majority $(75 \%)$ having a diploma or certificate in education, $3(18.75 \%)$ having a bachelor's degree and only $1(6.25 \%)$ having acquired a masters' degree. Thirteen $(81.25 \%)$ teachers were married, $2(12.5 \%)$ were single and one $(6.25 \%)$ was widowed. The respondents' teaching experience ranged from 5 to 23 years with an average experience of 15 years. Since the respondents were relatively mature, of varied academic qualifications and having relatively sufficient teaching experiences, one would infer that the information they provided would be authentic and reliable.

Section B: Perceptions about the Role of Language

Table 2 illustrates the null hypotheses ( 2 to 5) regarding the perceptions or views of primary school teachers about the role of language in the teaching and learning of mathematics and the related frequencies of those who agreed or disagreed. [SA=Strongly Agree, A=Agree, U=Undecided, D=Disagree, SD=Strongly Disagree].

Table-2. Teachers' perceptions about the role of language and related frequencies, $n=16$

\begin{tabular}{llllll}
\hline Null Hypothesis & SA & A & U & D & SD \\
\hline $\begin{array}{l}2 \mathrm{H}_{0} \text { : Performance in mathematics does not depend on the language of learning } \\
3 \mathrm{H}_{0} \text { : Performance in mathematics does not depend on the language of }\end{array}$ & $\begin{array}{l}0 \\
\text { instruction }\end{array}$ & 3 & 1 & 1 & 9 \\
$\begin{array}{l}4 \mathrm{H}_{0} \text { : Continued difficulty of mathematical understanding due to language does } \\
\text { not develop negative attitudes towards mathematics }\end{array}$ & 3 & 1 & 0 & 5 & 7 \\
$\begin{array}{l}\text { 5 } \mathrm{H}_{0} \text { : Lack of understanding of mathematics due to language does not generate } \\
\text { fear of mathematics }\end{array}$ & 0 & 2 & 1 & 5 & 8 \\
\hline
\end{tabular}

From Table 2 and combining SA and A and SD and D, one notes that $100 \%$ of the respondents rejected $2 \mathrm{H}_{0}, 62.5 \%$ rejected $3 \mathrm{H}_{0}, 75 \%$ rejected $4 \mathrm{H}_{0}$ and $81.25 \%$ rejected $5 \mathrm{H}_{0}$. These results confirm findings cited in the literature (Buhmann and Trudell, 2008; Awan, Azher, Anwar, and Naz, 2010); Abubakar, Umar, and Musawa, 2015). However, those who did not reject the null hypotheses had their own reasons which are discussed in the qualitative data analysis below.

\subsection{Teachers' Questionnaire (Qualitative) Data}

Teachers (coded as T1 to T16) were requested to give comments or explanations as to why they agreed or disagreed with the statements in Section B (or to Hypotheses 2 to 5). Some respondents referred to the learner's first language (L1) as 'mother tongue' while some referred to it as 'indigenous language' and the researcher inferred the terms to mean the same thing. With regards to $2 \mathrm{H}_{0}$ all the teachers disagreed that performance in mathematics does not depend on the language of learning and some of the reasons were:

T2: Most learners tend to participate a lot if the teacher blends English and L1.

T6: I disagree because learners will never be examined using the indigenous languages, thus their performance depends on the language of learning which is currently English.

T15: You cannot grasp the concept if you don't understand the terms used.

Further asked whether they believed that standard English is the best language for learning mathematics, some respondents pointed out that:

T1: ... because it's a universal language for pupils of different tribes and races.

T8: I feel all subjects should be introduced using the language the examiners use.

T11: If delivered in English you can understand better.

T13: Maths is taught and written in English hence language should meet leaners' minimum level of understanding.

The above sentiments expressed by teachers seem to agree with Mulwa (2014) who cited findings of some studies pointing out to the fact that good command of English plays a role in the leaner's performance in mathematics and that there is a high correlation between English reading and achievement in mathematics.

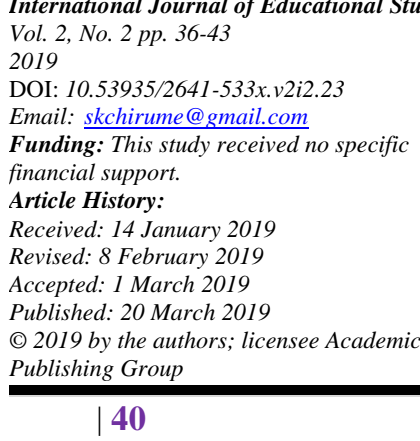


With regards to $3 \mathrm{H}_{0}$ (Performance in mathematics does not depend on the language of instruction), and to whether mother tongue should be used to teach mathematics or not, the respondents had mixed opinions, of which some were:

T2: No, performance depends on the language of teaching and at primary level it should be mother tongue which is easily understood by pupils.

T9: Teachers should not use mother tongue. Use of English should be strictly adhered to.

T14: Mother tongue does not clearly explain technical terms in maths.

T16: Its quite true because most of the leaners grasp concepts easily though L1.

The respondents were further asked to comment on whether learners understand mathematics skills and concepts more clearly if the teacher instructs them in both English and their mother tongue. Some of them made the following remarks:

T3: ... because it (mother tongue) helps in explaining difficult words, so a mixture is $O K$

T4: A good start will yield good and effective results. Maths should be taught in English.

T7: In actual fact there is not even one concept that you can use indigenous language without mixing with English.

T10: Maths language and terms are scientific and English is the vehicle through which concepts are relayed. I say NO to mixing.

T12: English should be used strictly and mother language where there are difficulties in explaining.

T13: This is evident when you are teaching, if you don't include mother tongue most, your learners are likely to perform a bit below standard.

The above points (on the challenges one would likely face when using mother tongue) were also raised by Kaphesi (2002) while a study by Ahmad, Jaaman, Majid and Rambely (2013) found out that students were fully convinced that the teaching and learning of mathematics would produce effective results if conducted in Malay (mother tongue) language.

With regards to $4 \mathrm{H}_{0}$ (Continued difficulty of mathematical understanding due to language does not develop negative attitudes towards mathematics), some respondents had this to say:

T4: I do not agree with this statement because if leaners fail to understand maths because of difficult words and symbols, surely they will develop negative attitudes towards the subject and this might lead to failure.

T11: When I was in Form 1, I had negative attitudes towards mathematics because NGM Exercise $11 \mathrm{~g}$ was too tough due to its technical and difficult language. [The book being referred to is New General Mathematics, New Edition, Book 1, authored by J.B. Channon, A. Mcleish Smith and H.C. Head and published in 1970 by Longmans: Harlow].

The hypothesis $5 \mathrm{H}_{0}$ (Lack of understanding of mathematics due to language does not generate fear of mathematics) was not supported by the following statements:

T5: The statement is false because I have read a paper which says if someone fails maths due to any reason, he/she will begin to develop fear of the subject.

T16: Most pupils who are afraid of mathematics point to its difficulty in terms of its language, symbols and strict or rigid formula.

Findings pointed out above (for $4 \mathrm{H}_{0}$ and $5 \mathrm{H}_{0}$ ) agree with points raised in previous studies (e.g., Mji and Makgato, 2006; Chirume and Chikasha, 2014).

\section{Conclusion}

This study concludes that there were significant differences (in favour of the English language) between Grade 5 learners' performance in a Maths multiple choice test presented in English and Grade 5 leaners' performance in the same test but presented in the Shona language. Although other studies concluded that students performed better in mathematics when they were taught in their mother tongue, teachers in this study had mixed feelings about the use of mother tongue. This study also concludes that performance in mathematics depends on the language of learning and the language of instruction. It was also established that 
most respondents agreed to the hypotheses that continued difficulty of mathematical understanding due to language develops negative attitudes towards mathematics (Research Question 1) and that lack of understanding of mathematics due to language generates fear of mathematics (Research Question 2). On using mother tongue to teach or examine learners in mathematics, respondents had mixed feelings, hence Research Question 3 (How does the use of mother tongue influence primary school learners' performance in a mathematics test?) had no straightforward answer.

The limitations of the study could be that the tests had few items, and that it was difficult to translate the questions into Shona since Shona language lacks suitable mathematics terminology and symbolism. Nonetheless, the study was a stepping stone towards answering Mufanechiya and Mufanechiya's (2011) questions: Using mother tongue as a medium of instruction in the teaching of mathematics in the Zimbabwean junior primary schools: Desirable or feasible?

\section{Recommendations}

This study recommends that:

Zimbabwean primary school teachers, textbook writers and educators should be capacitated and resourced to translate mathematical terminology into local languages (mother tongue) of the leaners.

Primary school teachers should be allowed and encouraged to teach mathematics, whenever possible and necessary, in the mother tongue of the learners.

More mathematics tests (not only involving Grade 5) in both English language and mother tongue of the learners should be written on a wider scale to firmly establish which group(s) would perform better.

There is need for further research and policy formulation on the language of learning and/or instruction at various school levels in order to enhance learners' performance, creativity and innovations leading to sustainable development.

\section{References}

Abubakar, H., Umar, S. A., \& Musawa, B. I. (2015). The impact of language in the teaching and learning of mathematics at junior secondary school in Katsina. International Journal of Research \& Development Organisation, 2(12): 616.

Ahmad, R.R., Jaaman, S.H., Majid, N \& Rambely, A.S. (2013). Challenges in Teaching and Learning Mathematics in the Transition to English Medium. Recent Advances in Educational Technologies. Available from http://www.wseas.us/e-library/conferences/2013/CambridgeUSA/EET/EET-25.pdf. [Accessed 7/5/18].

Awan, R. N., Azher, M., Anwar, M.N. \& Naz, A. (2010). An Investigation of Foreign Language Classroom Anxiety and its Relationship with Students' Achievement. Journal of College Teaching \& Learning 7(11): 33-40.

Buhmann, D. \& Trudell, B. (2008). Mother tongue matters: Local language as a key to effective learning, Paris, UNESCO.

Chirume, S. \& Chikasha, A.S. (2014). A Critical Analysis of the Factors Affecting Achievement in Secondary School Mathematics in Zimbabwe: A Case Study of Gweru District. Merit Research Journal of Education and Review, 2(9): 194-202.

Cummins, J. (1981). Linguistic interdependence and the educational development of bilingual children. Review of Educational Research, 49: 222-251.

Flouris, G., Calogiannakis-Hourdakis, P., Spiridakis, J. \& Campbell, J.R. (1994). Tradition and socio-economic status are Greek keys to academic success. International Journal of Educational Research, 21(7): 705-712.

Hafiz, M. and Farik, M. (2016). Effectiveness of teaching and learning mathematics using children's home language and cultural tools. International Journal of Scientific \& Technology Research, 5(1): 123-127.

Horwitz, E.K. (2001). Language anxiety and achievement. Annual Review of Applied Linguistics, (21): 112-126.

Kaphesi, E.S. (2002). The use of language in mathematics teaching in primary schools in Malawi: Bringing language to the surface as an explicit feature in the teaching of mathematics. PhD thesis, University of Nottingham. Available from http://eprints.nottingham.ac.uk/14002/1/395630.pdf. [Accessed_14/4/18].

International Journal of Educational Studies Vol. 2, No. 2 pp. 36-43

2019

DOI: $10.53935 / 2641-533 x . v 2 i 2.23$

Email: skchirume@gmail.com

Funding: This study received no specific

financial support.

Article History:

Received: 14 January 2019

Revised: 8 February 2019

Accepted: 1 March 2019

Published: 20 March 2019

(C) 2019 by the authors; licensee Academic

Publishing Group

42
Kazima, M. (2008). Mother Tongue Policies and Mathematical Terminology in the Teaching of Mathematics. Pythagoras 67: $56-63$

Mji A. \& Makgato, M. (2006). Factors associated with high school learners' poor performance: a spotlight on mathematics and physical science. South African Journal of Education, 26(2): 253-266.

Mufanechiya, A. \& Mufanechiya, T. (2011). Using mother tongue as a medium of instruction in the teaching of mathematics in the Zimbabwean junior primary schools. Desirable or feasible? Journal of Asian Scientific Research, 1(4): 194-203. 
Mulwa, E.C. (2014). The Role of the Language of Mathematics in Students' Understanding of Number Concepts in Eldoret Municipality, Kenya, International Journal of Humanities and Social Science, 4(3): 264-274.

Nziramasanga Commission (1999). Report of the Presidential Commission of Inquiry into Education and Training. Harare: Government Printers.

Sfard, A. (2008). Thinking as communicating: human development, the growth of discourses, and mathematizing. Cambridge, UK: Cambridge University Press. 